\title{
A Brave New Dawn? Digital Cakes, Cloudy Governance and Citizenship á la Carte
}

\author{
Jelena Džankić
}

I have always been fascinated by the human capacity to imagine future worlds and describe what humanity would look like in the years or decades ahead. In the second half of the nineteenth century, Jules Verne wrote about electricity, submarines and flying balloons. A few decades later, Thea von Harbou and Fritz Lang gave birth to the world of Metropolis, which in many ways is a metaphor of contemporary societies. In the 1970s and 1980s, Isaac Asimov wrote about psychohistory, a discipline that combines statistics, psychology and history to predict how the behaviour of large groups would shape future events. Just as most of the things described by Verne, von Harbou and Lang, or Asimov seemed technologically and politically distant or unimaginable at their times, so do meaningful digital communities seem to be today.

Liav Orgad sees tremendous potential in digital technologies for reconstructing the traditional notion of citizenship by shifting status, identity and the exercise of rights away from the state and closer to the individual. He believes that blockchain could enhance the current structure of international governance by strengthening human rights through the attribution of digital identities and by offering new models for political participation through cloud communities, which in turn would decrease the inequality engrained in, for instance, the principles of voting in the United Nations. In other words, with further development of blockchain technologies, states would no longer be the sole determinants of an individual's legal status, or have the monopoly over the exercise of individual rights, or be the core community for identity ascription. In this sense, I am in agreement with Orgad, Primavera De Filippi and Francesca Strumia that we cannot but acknowledge that rapidly developing technologies are likely to 'outsource' many of the state's functions to cyberspace. Even so, as has been pointed out by other contributors (Rainer Bauböck, Robert Post, Michael Blake and Peter Spiro), blockchain technologies and cloud communities raise a number of concerns about governability and the exercise of self-sovereignty. 


\section{They want citizenship? Let them have digital identities instead!}

In his kick-off contribution Orgad highlights that 1.1 billion people, or a sixth of the global population lack an official identification. Such people, including many refugees, displaced persons, nomadic pastoralists or socially marginalised minorities like the Roma are consequently excluded from participating in or accessing services of modern states. According to Orgad, blockchain technologies already provide the infrastructure for attributing such people global digital IDs, which would grant them recognition as 'human beings'. Blockchain-based digital IDs would enable individuals to create and register their own identity. This identity would be validated through multiple decentralised network nodes. It would also be permanent and immutable.

I agree with the general need to recognise every human being before the law. However, the attribution of a global digital ID scarcely resolves this problem for two reasons. The first one is recognition. Our legal status is attributed by states recognising us as legal persons. The international system of mutual recognition among states allows us to be considered a legal persona elsewhere precisely because the status that we have has been confirmed by a state. Hence, any global digital ID would still need to be recognised by states or an international organisation in order to have external validity. Initiatives, such as ID2020 ${ }^{1}$ speak about the need to tackle the problem of the lack of 'officially recognised identity' through digital technology but offer scarcely any practical pointers as to how these identities would be recognised and by whom. Furthermore, if such digital identification were to create a 'status and identity complementary to national citizenships', I am wondering what kind of status and rights it would yield for those whose predicament Orgad seeks to resolve. If a digital ID has no external recognition, it has little value for a person with no other proof of identity. They will still lack the status that a digital identity could complement but cannot substitute for. Isn't the offer of digital identity for them a bit like Marie Antoinette's cake for the hungry crowds in revolutionary Paris?

\footnotetext{
ID2020 Alliance at a Glance, available at https://static1.squarespace.com/ static/578015396a4963f7d4413498/t/5a5f92bcc8302548e 722 dff3/1519157409748/ID2020+Alliance+Doc+-+Jan+2018.pdf
} 


\section{Governance by blockchain: digital hierarchies or direct democracy?}

Orgad's second claim looks prima facie stronger. Recent experiments with blockchain-based virtual communities, such as Bitnation, indicate that blockchain technology has the potential to substitute or complement some elements of state governance. In theory, in a blockchain-based cloud community, members agree on a set of laws regulating their interaction, and these laws are then amended by consensus.

Pazaitis, De Filippi and Kostakis give the example of Backfeed (http:// backfeed.cc/) protocol as a conceptual model 'for a new form of governance with an incentivisation system implemented on the blockchain.'2 This system would be materialised through an organisational structure of decentralised cooperation based on peer-to-peer evaluation and a reputation system as grounds for allocating communal influence. This kind of cooperation would presume that a number of members come together to establish a digital community and reach a consensus on what values underpin that community. Members of the community own certain initial amounts of 'reputation' tokens and they are incentivised to participate in communal decisions through a system that provides reputational gains to those who are best aligned with communal values. Those contributing voluntarily to 'values' receive a reward if 50 per cent of the tokens representing the community's reputation have been invested in the evaluation of the voluntary contribution. The reward takes the form of reputation tokens, which are shared between the contributor and those who reached the consensus on the evaluation. Whenever a person evaluates a new contribution, they also give away some of their existing reputation to it.

Let's translate this into a thought experiment. Imagine there is a Backfeedbased community called Scientia, in which the core value were 'knowledge'. Scientia has been created by five members (A, B, C, D, and E), each of whom originally had 10 reputation tokens (i.e., the community has a total of 50 tokens). Member A comes up with a proposal to create an encyclopaedia of cloud communities and the proposal is put to communal vote. Votes can range from 1 to 5 (1 lowest contribution, 5 highest contribution). The proposal will go through if at least 25 reputation tokens have been invested in the evaluation.

2 Pazaitis, A., P. De Filippi \& V. Kostakis (2017), 'Blockchain and value systems in the sharing economy: The illustrative case of Backfeed', Technological Forecasting and Social Change 125: 105-115, at 111. 
Now, imagine a scenario where A invests 8 out of her initial 10 reputation tokens with a vote of 5 ; B invests 5 tokens with a vote of 5 ; C invests 3 tokens with a vote of 3; D invests 5 tokens with a vote of 4 ; E invests 7 tokens with a vote of 5 . A total of 28 tokens have been invested, with three contributors voting 5 , and hence the proposal is accepted. C and D will lose the 8 tokens they invested, and these will be distributed between A (4 tokens), B (3 tokens), and E (1 token) in line with their initial reputation investment. The new count of reputation tokens would be 14 for $\mathrm{A}, 13$ for B, 7 for $\mathrm{C}, 5$ for $\mathrm{D}$, and 11 for $\mathrm{E}$. In evaluating the subsequent proposal, A, B and $\mathrm{E}$ would have greater voting power, as they would hold three quarters of the community's reputation tokens.

In my view, there are three problems with this kind of decision-making. First, the 'overall evaluation of a specific contribution is based on the reputation score'. ${ }^{3}$ This implies the use of a system of weighted voting, whereby individuals with higher reputation (i.e., with more tokens) have a greater say in communal decision-making. Paradoxically this would make the principles of deciding in such digital communities closer to those in ancient Rome, feudal Prussia, or French colonies where votes were weighted on grounds of 'wealth' than to contemporary democracies based on the equality of votes. In other words, this kind of system would perpetuate inequality of membership in a similar way as the Chinese social credit system described by Costica Dumbrava does. Second, even though the general idea of Backfeedbased governance is to incentivise participation through rewards, those with high rewards from previous rounds of evaluations may be less inclined to participate in new evaluations as that may result in their loss of reputation. Equally, 'losers' in the communal vote (such as the examples of C and D above) may face obstacles in putting forward or voting for any proposal due to limited resources at their disposal. Third, such a system could create incentives to bet with the winners rather than to invest into the values that one truly believes are in line with communal ones. This is antithetical to democracy and turns into a market where people pursue reputational gains instead of deliberating on what values they share. That is, a system in which reputation is gained and lost by 'betting' on the levels of contribution to communal value has the potential to create a stratified society in which decisions are made by a small number of those willing to speculate on communal value.

An alternative to this would be to think how direct democracy could work in cloud communities. Presumably, protocols could be developed

\footnotetext{
3 Above n. 1 at 110.
} 
that - unlike Backfeed - base decision-making on equal voting power for each digital identity and that offer a platform for deliberation rather than only for voting. Such communities would be similar to voluntary associations of individuals that adopt statutes providing for internally democratic governance: all members (independently of their duration of membership and place of residence) and members only can participate in decisions taken by the 'demos' of the association.

Now, let's go back to the example of Scientia. Imagine that this time, Scientia were a voluntary decentralised blockchain-based community that operates on the basis of equal votes of its members A, B, C, D, and E. The community votes on A's proposal for the encyclopaedia of cloud communities and the proposal passes due to positive votes of A, B, and E. Unlike in the previous example, since there are no reputational gains or losses, $\mathrm{C}$ and $\mathrm{D}$ will have the same voting power in the next ballot. Hence such a model would not disincentivise those who opposed the initiative. However, it would then not provide incentives for contributing in the future, as Backfeed is supposed to do. As Pazaitis, De Filippi and Kostakis rightly point out, this would lead to "to the gradual dissipation of the community members, who could no longer reflect themselves into the value system of the new entity."

So there is a dilemma of blockchain governance in cloud communities: will they be based on incentives that create hierarchies or on direct democracy with scarce mechanisms for motivating participation?

\section{Citizenship as a business model?}

In his kick-off contribution Orgad notes that the future of citizenship is dynamic and multi-layered. Yet so is the present, and so has been its past. The key question is whether we are ready to embrace a new approach to citizenship, based on 'smart contracts' operating in cyberspace and regulating needs of individuals, just as a business model would do. For Spiro the recent trend towards a global market for passports exemplifies such an approach to citizenship: individuals with multiple passports have more choice where to settle, pay taxes, send their children to school, etc. Hence, in some respects, citizenship (albeit for a small number of people who can benefit from investor citizenship programmes) is already merely an access point to a market of goods and services that different providers (in this case states) offer.

As new technologies develop, digital markets will allow individuals to choose the services previously provided by the state from private companies.

4 Ibid. 
Indeed, some functions of the state have already been outsourced to companies operating in the digital world (e.g., online education instead of public schooling, car-sharing schemes instead of public transport, etc.). Perhaps the utopian vision of the 'sharing economy' is that public goods would be produced through horizontal and voluntary cooperation among consumers. Yet examples such as online degrees, Airbnb, Uber, and the likes prove the contrary. They follow the logic of the market and reveal the huge potential for corporate power based on network effects and 'cartelisation' of services. ${ }^{5}$ In considering the effects of citizenship as a business model, we also need to think about possible implications for some other core functions of the state, including adjudication and the provision of security.

And even if, in the spirit of the introductory paragraph, digital technologies bring along numerous benefits we have to recognise that their $a$ la carte approach is hardly conducive to the creation of a community of shared values among members. That is, it is hardly conducive to citizenship.

Open Access This chapter is licensed under the terms of the Creative Commons Attribution 4.0 International License (http://creativecommons.org/licenses/by/4.0/), which permits use, sharing, adaptation, distribution and reproduction in any medium or format, as long as you give appropriate credit to the original author(s) and the source, provide a link to the Creative Commons license and indicate if changes were made.

The images or other third party material in this chapter are included in the chapter's Creative Commons license, unless indicated otherwise in a credit line to the material. If material is not included in the chapter's Creative Commons license and your intended use is not permitted by statutory regulation or exceeds the permitted use, you will need to obtain permission directly from the copyright holder.

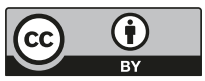

5 Atzori, M. (2015), 'Blockchain technology and decentralized governance: Is the state still necessary?', available at SSRN: https://ssrn.com/ abstract=2709713 or https://doi.org/10.2139/ssrn.2709713 